\title{
Pedagogical Diagnostics of Auditory-Speech Development of Children with Hearing Impairment of Preschool Age: Methodology and Results
}

\author{
Svetlana N. Feklistova* \\ Belorussian State Pedagogical University named after Maxim Tank, 220030, Minsk (Belarus), 18, Sovetskaya street, \\ feklsv@mail.ru
}

\begin{abstract}
The Republic of Belarus has the prerequisites for a significant increase in the potential for the development of auditory perception and speech of children with hearing impairment: socio-economic, medical, technical, psychological, pedagogical and sociocultural. Audiological screening, early hearing prosthetics, high-tech hearing aids and an early pedagogical assistance system have been introduced. These factors create opportunities for children with hearing impairment to switch to the "natural path" of speech development, but itself they do not guarantee high result. The most important condition is an adequately correctional work with the child.

One of the main principles of special pedagogy is the diagnostic basis of education: determination of the current level and development potential of the child. This requires the development of high-quality diagnostic tools, criteria for evaluating the results. So, the relevance of the study is due to the contradiction between: 1) the increased capabilities of the auditory-speech development of children with hearing impairment due to using of medical and technical means; 2) insufficient knowledge of the current level of development of hearing and speech in new condition; 3) lack of appropriate pedagogical diagnostic methods.

The purpose of the article is to develop and characterize the author's methodology pedagogical diagnostics of the auditory-speech development of children with hearing impairment and to study the specifics of their auditory-speech development.

The leading research method is empirical. The article presents the author's diagnostic tools, criteria and indicators for assessing functional auditory and speech capabilities of children with hearing impairment of preschool age. The special educational needs of deaf and hard-of-hearing children have been studied and characterized. It is new basis for the differentiated approach in correctional work.
\end{abstract}

Keywords: hearing impairment, auditory-speech development, auditory perception; oral speech; complex pedagogical diagnostics of auditoryspeech development; special educational needs.

\section{(C) 2020 Svetlana N. Feklistova}

This is an open access article distributed under the terms of the Creative Commons Attribution License (CC BY 4.0), which permits unrestricted use, distribution, and reproduction in any medium, provided the original author and source are credited.

Published by Kazan federal university and peer-reviewed under responsibility of IFTE-2020 (VI International Forum on Teacher Education)

\footnotetext{
*Corresponding author. E-mail: feklsv@ mail.ru
} 


\section{Introduction}

One of the key tasks of modern education for children with special needs is preparing for independent living, creating the conditions for maximum socialization and integration in society. The hearing and speech development of children with hearing impairment is a key factor in the effectiveness of their educational and social integration (Guberina, 2013; Korolyova, 2019; Löwe, 2003). The quality of the development of auditory perception and speech will determine the success of teaching a child with hearing impairment at the levels of preschool and school education, and subsequently, the possibility of free professional choice, employment, achieving a certain social status, ensuring one's own life and family life. In studies on the problems of teaching deaf and hard of hearing children, it is noted that the range of hearing development of children with hearing impairment is very wide: from practical compliance with regulatory indicators to a sufficiently low one that does not provide effective communication. In this regard, the urgent problem is the pedagogical study (diagnostics) of the state of development of auditory perception and speech of children with hearing impairment and a description of their functional level of auditory-speech development. This will help to determine the most effective methods and means of further education of a child with hearing impairment.

\section{Purpose and objectives of the study}

The purpose of the study is to experimentally study and characterize the specifics of the auditory-speech development of children with hearing impairment of preschool age and their special educational needs in this area using the author's tools of pedagogical diagnostics.

\section{Literature review}

The current stage is characterized by the appearance of prerequisites for a significant change in the level of auditoryspeech development of children with auditory deprivation: medical and technical (early diagnosis, early hearing prosthetics, the use of high-tech means to compensate for hearing impairment), psychological and pedagogical (the possibility of real use of sensitive periods of development of hearing and speech, the implementation of habilitation measures to prevent or reduce the severity of developmental disorders of the second and third orders), sociocultural (the transition from the "medical" to the "social" model of rehabilitation). Indeed, the introduction of cochlear implantation and the use of modern high-tech digital hearing aids significantly increase the possibility of functional hearing development. It creates the prospect for a child with hearing impairment to reach a higher level of speech development. However, this becomes possible only if the timely and adequate pedagogical work with the child is realized (Kobrina \& Denisova, 2010; Korolyova, 2019; Löwe, 2003).

It is necessary to rethinking of the scientific and methodological system of correctional work of children's with hearing impairment oral speech and auditory perception development. Psychological and pedagogical diagnostics of development is aimed at identifying the level of actual development of the child and predicting the potential for its development. Diagnostic results are the basis for determining the conditions of training and education necessary for a particular child.

The priorities of modern education in many countries of the world include the inclusion of children with special needs in the general educational system, and the transition to inclusive education (Korolyova, 2019; Kukushkina et al., 2017). Achieving this strategic goal in the education of children with hearing impairment is possible only if we create an 
educational and social environment that takes into account the opportunities and limitations of the child and will contribute to the further development and realization of children's educational potential.

At the present stage of development of special pedagogy, there is a transition from orientation toward a "defect" to a strategy for accounting for the special educational needs (SEN) of children. This makes it necessary to change the targets and technology of pedagogical study and assessment of the auditory-speech development of children with hearing impairment (Lubovsky, 2013; Chulkov et al., 1990; Malofeev, 2019). The results of pedagogical diagnostics should also be changed.

An analysis of modern methods of pedagogical diagnostics of the development of auditory perception and speech of children with hearing impairment showed that they are of a "separative nature", focused on the "medical model" of rehabilitation. We have developed a method for the complex functional pedagogical diagnostics of the auditory-speech development of children with hearing impairment. It includes an assessment of the development of hearing and speech, taking into account various grounds: components of speech activity, language levels, forms of connected speech. Our method is aimed at identifying and characterizing individual SEN of children with hearing impairment in the field of auditory-speech development as the basis for determining and creating appropriate special educational conditions.

It is very important to use the pedagogical diagnostics of auditory-speech development at the stage of transition from the preschool to the level of general secondary education, because its results largely characterize the readiness of children with hearing impairment to study at school. Studying the state of auditory-speech development of children with hearing impairment at the stage of completion of preschool education will help us:

- $\quad$ to correctly determine the child's further educational route;

- $\quad$ to characterize the subject, spatial, socio-psychological resources necessary for successful learning;

- $\quad$ to determine appropriate teaching methods and means;

- $\quad$ to determine an acoustic conditions that ensure adequate perception and understanding educational material.

\section{Methodology}

In the research process, the following methods were used: theoretical (analysis, synthesis, generalization, systematization); empirical (stating experiment); methods of mathematical statistics (Pearson correlation coefficient, Mann-Whitney U-test).

\section{Research Methodology}

The content of pedagogical diagnostics of the auditory-speech development of children with hearing impairment of preschool age has certain specificity, which is due to the need to determine the degree of readiness of the child to study at school. At preschool age, the basics of mastering children by coherent speech (dialogic and monologic) are being formed, and text skills are being formed and developed as prerequisites for textual competence important for learning. This served as the basis for the implementation of the analytical-synthetic principle in determining the content and procedure of 
pedagogical diagnostics of the auditory-speech development of children with hearing impairment at this stage. Diagnostic tools include three blocks: perception; understanding; active speech.

The block "Perception" is aimed at identifying the functionality of auditory perception of speech material of varying degrees of complexity. The importance of the implementation of the tasks of this unit is due to the fact that the adequacy of the perception of speech information depends on the adequacy of auditory images of a child with hearing impairment. The auditory images stored in the human memory serve as a kind of standard with which the incoming acoustic signal is subsequently compared. Based on this comparison, the child "recognizes" a particular speech unit and controls the quality of their own speech. Thus, the degree of differentiation of speech material in perception affects the quality of understanding and speech production. The structure of the block "Auditory Perception" includes four tasks: 1) the perception of words; 2) the perception of sentences; 3) the perception of sentences with a gradual increase; 4) the perception of words and phrases against the background of mildly expressed noise interference. The evaluation criteria are: perception volume; the degree of complexity of perceived speech units; level of formation of auditory representations; prevailing mode of perception; ability to perceive speech on the background of interference.

The task of the "Understanding block" is to identify the skills of semantic processing and interpretation of speech information. The need to include this task is due to several reasons. Firstly, by reducing the volume of passive and active vocabulary of children. Secondly, the thinking patterns of children with hearing impairment, which are manifested in the inability to establish causal and other types of relationships in the structure of sentences and texts. Thirdly, frequent formal mastery of speech turns that the child remembers without understanding the meaning. The task provides answers to two types of questions based on the picture. The first type is aimed at revealing the facts described in the proposal and includes the questions "Who?", "What does it do?", "Where?", "When?". The second type requires the establishment of hidden dependencies and relationships and provides questions "Why?" "For what?". The evaluation criterion is the level of understanding: factual or semantic.

The "Active Speech block" provides for the identification of children's skills in building coherent statements. It includes two tasks.

The first diagnostic task of the block involves the auditory-visual perception of the text and its retelling. The criteria for evaluating the first task of this block are the integrity and coherence of monological statements. Assessing the integrity of coherent reproductive statements requires the teacher to draw up a scheme of the full semantic structure of the text based on the definition of semantically necessary sentences, allowing to convey the meaning of the text. Variants of retelling of children are compared with this scheme.

The second task involved a dialogue initiated by an adult. The third task is aimed at encouraging the child to request information. Determining the criteria for assessing tasks related to the study of dialogical speech skills, we took into account modern data of psycholinguistics on the structure of dialogue. The basic unit of dialogue is dialogic unity (stimulus - response). The criteria were the skills of the child:

- to perceive and understand the replica of the interlocutor;

- to formulate a replica-reaction that is adequate in form and content; 
- to initiate communication (formulate replica incentives).

In assessing all three tasks, the adequacy of the selection of lexical and grammatical means was taken into account.

\section{Experimental base of research}

The experimental base of the research was the institutions of preschool education of the Republic of Belarus: "Republican Center for Preschool Children with Hearing Impairment"; "Day nursery garden number 541" (Minsk); "Nurserykindergarten No. 469 for children with special needs” (Minsk); “Nursery Garden No. 51” (Grodno).

\section{Results}

The study involved 33 children with hearing impairment from 7 to 8 years age, which is $26 \%$ of the total population of this group in the republic. The control group ( $\mathrm{CG}, 17$ people, 2 group groups) consisted of children studying according to the traditional method. The experimental group (EG, 16 people, 2 group groups) included children who studied using the author's integrative technology for the development of auditory perception and oral speech (Feklistova, 2019).

The results of the study allow us to conclude that a wide range of auditory-speech development of children with hearing impairment of older preschool age is expressed in the differences in all studied parameters: the volume and degree of complexity of adequately perceived speech information by ear (from 30 to 95\%); the influence of the type of "auditory" errors on the meaning of speech units; the level of formation of auditory representations; understanding perceived information at the levels of the semantic syntactic whole, individual sentences or words; the degree of formation of the ability to reproduce a program of a coherent monological message; abilities to carry out dialogical communication using different types of dialogical unity.

We have identified four levels of formation of each of the components of the auditory-speech development of children with hearing impairment at the stage of completion of education at the level of preschool education (transition to the I stage of general secondary education): optimal, sufficient, reduced and limited. We characterize each of them.

Perception. Optimum level: adequate perception (accurate differentiation) by ear of $80 \%$ or more of the total volume of speech material, including similar acoustic characteristics; single auditory errors that do not distort the meaning of speech units; differentiated speech perception at the background noise level. Adequate level: adequate hearing perception from 50 to $79 \%$ of the total volume of speech material; auditory errors in the perception of acoustically close speech material (distortions and replacements), omissions of individual elements; difficulties in speech perception at the level of noise interference. Decreased level: auditory perception from 20 to $49 \%$ of the total volume of speech material; lack of differentiation of acoustically close speech material; a significant number of omissions of speech units and auditory errors affecting the meaning of words (replacing a "random character" with words similar in sound; distortion); a sharp decrease in perception performance against the background of interference. Limited level: perception of less than $20 \%$ of the total volume of speech material, multiple omissions and distortions of the speech units of the text; deterioration in the results of perception against the background of interference.

Understanding. Optimal level: understanding at the level of a semantic syntactic whole with single errors in establishing logical connections. Sufficient level: understanding the content of speech utterances at the levels of factual and partially 
semantic analysis, the presence of errors in establishing logical connections. Reduced level: speech understanding is reduced, only a partial factual analysis is available. Limited level: understanding at the level of individual words.

Active speech. Optimal level: a sufficiently complete reproduction of the monologic message program with separate omissions of speech units that do not violate the overall integrity of the storytelling. The ability to continue and initiate a dialogue on a familiar topic, using question-answer dialogical unity. Adequate selection and use of lexical and grammatical means, single grammatical errors. Sufficient level: reproduction of a monological message with the omission of individual semantic links. The ability to respond to incentive remarks during dialogue, difficulties in initiating dialogue on familiar topics (limited volume - up to 2 dialogical units). Predominantly adequate selection and use of vocabulary; the presence of agramatic sentences. Reduced level: fragmented reproduction of text with a strong violation of the integrity. Significant difficulties in dialogue. Marked difficulties in the selection and use of lexical and grammatical means. Limited level: in the reproduction of monological statements - a sharp violation of the integrity of the text, expressed in the naming of individual speech elements. The ability to conduct a dialogue is not formed. Marked difficulties in the selection and use of lexical and grammatical means, the use of inadequate verbal replacements.

As the analysis of the data showed, children in the experimental and control groups showed different levels of formation of the studied components of speech activity. So, children of the experimental group showed optimal $(62.5 \%)$ and sufficient (37.5\%) levels of development of auditory perception. In children of the control group, optimal (29\%), sufficient (47.5\%), and reduced (23.5\%) levels were noted. In terms of "understanding of speech", the results also differ. In children of the experimental group, optimal (50\%), sufficient (44\%) and reduced (6\%) levels were recorded. In children of the control group - sufficient (18.5\%), reduced (70.5\%) and limited (12\%). The results of studying the active speech of children in the experimental group indicate the predominance of optimal (44\%) and sufficient $(50 \%)$ levels. Only $6 \%$ of children have a reduced level of active speech. At the same time, children from the control group mainly recorded a reduced level of active speech (82\%). A sufficient level was noted in $12 \%$ of children, and limited levels in $6 \%$.

An analysis of the results using the Pearson correlation coefficient $(\mathrm{p} \leq 0,05)$ indicated that control group the correlation of the indicators "perception - understanding" ( $\mathrm{r}=0.29)$, “perception - active speech" is poorly expressed $(\mathrm{r}=0.29)$. Between the indicators "understanding - active speech" the correlation is moderate $(\mathrm{r}=0.55)$. A strong correlation was noted in the experimental group between the indicators "perception - active speech" $(\mathrm{r}=0.7)$ and "understanding - active speech" $(\mathrm{r}=0.83)$; moderate connect between the indicators "perception - active speech" $(\mathrm{r}=0.48)$.

It should be noted that there is a "mismatch" ("asynchrony") in the levels of formation of individual components of the auditory-speech development in children of the control and experimental groups.

The results obtained indicate weak correlation in the levels of formation of the studied components. This became the basis for our development of a typology of the auditory-speech development of children with hearing impairment of preschool age. We have identified three main types.

Conditionally-normative development is characterized by the development of all components of auditory-speech development at the optimal or sufficient levels. 
Underdevelopment is expressed in reduced or limited levels of formation of all components of auditory-speech development in relation to normotypic indicators. A difference in the levels of development of individual components in the 1st stage is allowed (for example, a reduced level of development of auditory perception and a limited level of understanding and production of speech, etc.).

Asynchronous development is manifested in the uneven development of the components of auditory-speech development in the same child. We attributed this type of development to cases where the difference in the levels of formation of the individual components of auditory-speech development is 2 or more steps (for example, the optimal level of development of auditory perception, combined with reduced or limited levels of development of understanding and active speech, etc.).

This allows us to conclude about the effectiveness of the developed integrative technology for the auditory-speech development of children with hearing impairment. Based on the results of an empirical study, the special educational needs of children with hearing impairment in the field of hearing and speech development were characterized. These are the needs for mastery:

the ability to differentially perceive speech information in acoustic conditions of varying degrees of complexity (at different distances; speech of different loudness; in noise-insulated conditions and in noise conditions; when perceiving the speech of different speakers; when perceiving the speech of a direct interlocutor or audio recording, etc.);

the most accurate auditory images of different speech units;

the ability to restore incomplete or inaccurate speech units based on existing speech experience, to carry out a semantic analysis of coherent statements;

in the development, correction and refinement of the vocabulary, the expansion of the lexical fields of words;

in the development of the grammatical side of speech;

in mastering the skills of programming coherent statements.

The characteristics of these special educational needs will serve as the basis for the implementation of a differentiated approach in the process of correctional work with children with hearing impairment (deaf and hard-of-hearing).

\section{Discussions}

The problem of developing and implementing a social model of correctional work with children with special needs is one of the urgent issues in special pedagogy (Lubovsky, 2013; Malofeev, 2019). The basis for the implementation of the social model of rehabilitation is the development of new approaches in diagnosing the development of children. This is a transition from a model focused on "developmental disability (defect)" to a functional model. The result of the functional model of pedagogical diagnostics should be a characteristic of the special educational needs of children. Based on the description of special educational needs, special conditions for their training and education are modeled. So, earlier the main factor for determining the learning strategy for children with hearing impairment was the indicator "degree of hearing impairment" (medical diagnosis). 
Now this indicator is no longer the leading one. Highly effective hearing aids (digital hearing aids and cochlear implants) have been introduced and are being used. They significantly change the functional status of the child with hearing impairment and the possibility of learning. For example, a child diagnosed with deafness but using a cochlear implant today can achieve the same level of speech development as hearing children.

The study of the functional capabilities of the development of hearing and speech of children with hearing impairment and the identification of their special educational needs is promising.

\section{Conclusion}

At the present stage, the functional integrated pedagogical diagnosis of the auditory-speech development of children with hearing impairment is becoming relevant. It determines the child's ability to perceive speech by ear, the level of understanding of speech and the ability to independently produce statements. In order to determine adequate tasks, content and teaching methods for deaf and hard of hearing children, it becomes relevant to identify the specifics of their hearing and speech development. Our study allowed us to conclude that a wide variety of development of auditory perception and speech of children with hearing impairment of senior preschool age. Based on the results we have characterized the special educational needs of children with hearing impairment in the field of auditory-speech development. This will allow to implement a differentiated approach in education and achieve a higher quality of education.

\section{References}

Chulkov, V. N., Lubovsky, V. I., \& Martsinovskaia, E. N. (1990). Differentiative approaches to the teaching and upbringing of deaf-blind children. Moscow: Academia Pedagogicheskikh Nauk.

Feklistova, S. N. (2019). Integrative technology for hearing development in children with hearing impairment. Pedagogical science and education, 6, 78-86.

Guberina, P. (2013). Verbotonal method. SUVAG.

Kobrina, L. M., \& Denisova O. A. (2010). Abilitational work with deaf young children. St. Petersburg: LSU.

Korolyova, I. V. (2019). Rehabilitation of deaf children and adults after cochlear and brainstem implantation. St. Petersburg: Karo.

Kukushkina, O. I., Goncharova, E. L., \& Sataeva, A. I. (2017). Children with cochlear implants. Moscow: National education.

Löwe, A. (2003). Hörerziehung für hörgeschädigte Kinder. Geschichte - Methoden - Möglichkeiten.

Lubovsky,V. I. (2013). Special education needs. Psychological science and education, 5, 61-66. 
Malofeev, N. N. (2019). The concept of development of education for students with disabilities until 2030. Retrieved from https://fcprc.ru/wp-content/uploads/2019/05/Malofeev-N.N.-O-strategii-razvitiya-obrazovaniya-detei-sOVZ.pdf

Obuhova, T. I. (2016). Education and training of children with hearing impairment of early and preschool age. Minsk: Adukacia i vyhavanne. 